\title{
Determination of Antimony(III) and Total Antimony by Dispersive Liquid-Liquid Microextraction Combined With Electrothermal Atomic Absorption Spectrometry
}

\author{
Shuai Zhang and Zhefeng Fan* \\ Department of Chemistry, Shanxi Normal University \\ Linfen 041004, P.R. China
}

\section{INTRODUCTION}

Antimony exists in natural systems in several forms as antimonite [Sb(III)], antimonite [Sb(V)], and $\mathrm{Sb}$ associated with various inorganic and organic compounds or colloids (1). The toxicity of antimony compounds and their biological effects depend on the oxidation state, $\mathrm{Sb}$ (III) compounds being more toxic than pentavalent compounds (2). The total antimony concentration may not provide sufficient information to understand its toxicity, bioavailability, biotransformation, and other relevant aspects (3). Therefore, an accurate and reliable method for the determination of antimony species is more important than the total antimony measurement.

Since the concentrations of antimony in environmental water samples are very low, ranging from a few $\mathrm{ng} \mathrm{\textrm {L } ^ { - 1 }}$ in fresh water to $200 \mathrm{ng} \mathrm{L}^{-1}$ in the oceans $(4,5)$, sensitive analytical techniques are required. Inductively coupled plasma mass spectrometry (ICP-MS) $(6,7)$, hydride generation atomic absorption spectrometry (HG-AAS) $(8,9)$, inductively coupled plasma atomic emission spectrometry (ICP-AES) $(10,11)$, and electrothermal atomic absorption spectrometry (ETAAS) (12-14) are the methods recommended for this purpose. However, direct determination and speciation is difficult.

In order to achieve accurate, reliable, and sensitive results, separation and preconcentration procedures are often necessary prior to analysis. Many separation and pre-

\footnotetext{
*Corresponding autbor.

E-mail: zhefengfan@163.com

Tel: +863572051158
}

\begin{abstract}
A simple and sensitive method has been developed for electrothermal atomic absorption spectrometry (ETAAS) analsyis with $\mathrm{Rh}$ as the permanent modifier for the determination of $\mathrm{Sb}(\mathrm{III})$ and total $\mathrm{Sb}$ after separation and preconcentration by dispersive liquid-liquid microextraction. At $\mathrm{pH} 2, \mathrm{Sb}(\mathrm{III})$ is complexed with N-benzoyl-Nphenylhydroxylamine (BPHA) and extracted into the fine droplets. After extraction, the phase is separated by centrifugation and $\mathrm{Sb}$ (III) is determined by

Parameters such as pyrolysis and atomization temperature, disperser solvent type and volumes, extraction solvent type and volumes, $\mathrm{pH}$, and BPHA concentration were investigated. Under the optimized experimental conditions, the detection limit $(3 \sigma)$ was $0.03 \mu \mathrm{g} \mathrm{L}^{-1}$ for $\mathrm{Sb}(\mathrm{III})$. The relative standard deviation was $3.8 \%$ for $\mathrm{Sb}$ (III) (c=0.5 $\mu \mathrm{g} \mathrm{L}^{-1}$, $n=5)$. The enrichment factor was 110. The developed method was applied successfully to the determination of $\mathrm{Sb}$ (III) and total $\mathrm{Sb}$ in natural water samples with satisfactory results.
\end{abstract}

concentration methods involving solid-phase extraction $(15,16)$, single-drop microextraction (17), hydride generation $(18,19)$, and liquid-liquid extraction $(20,21)$ have been used for the determination of antimony species in environmental waters.

Recently, a microextraction technique based on a ternary solvent system has been developed. In this technique, termed dispersive liquid-liquid microextraction
(DLLME) (22), an appropriate mixture of an extraction solvent and a disperser solvent are rapidly injected into an aqueous sample so that a cloudy solution is formed. The analyte in the sample is then transferred to the fine droplets of the extraction solvent and phase separation is performed by centrifugation. The advantages of this method include its simplicity of operation, rapidity, low cost, low consumption of organic solvents, and high enrichment factors. The technique has been applied to the determination of trace organic pollutants and metal ions in environmental samples $(23,24)$.

The aim of this work is to combine DLLME with ETAAS and develop a new method for the determination of $\mathrm{Sb}$ (III) and total $\mathrm{Sb}$ in environmental water samples. N-benzoyl-N-phenylhydroxylamine (BPHA), a chelating agent which originates complexes with a number of metals, is used to extract $\mathrm{Sb}$ (III) into the organic phase and ETAAS with $\mathrm{Rh}$ as the permanent modifier is used for the determination of $\mathrm{Sb}$.

\section{EXPERIMENTAL}

\section{Instrumentation}

A Model TAS-990 atomic absorption spectrometer (Beijing Puxi Instrument Factory, Beijing, P.R. China), equipped with deuterium lamp background correction and transversely heated graphite atomizer, was used in this study. Pyrolytically coated graphite tubes (Beijing Puxi Instrument Factory, Beijing, P.R. China) were used. An antimony hollow cathode lamp was employed as the radiation source at $217.6 \mathrm{~nm}$. The spectral band pass 
was $0.2 \mathrm{~nm}$, operated at $5 \mathrm{~mA}$.The instrumental parameters used are summarized in Table I.

\section{Standard Solution and Reagents}

A stock standard $\mathrm{Sb}$ (III) and $\mathrm{Sb}(\mathrm{V})$ solution $\left(1.0 \mathrm{mg} \mathrm{mL}^{-1}\right)$ was prepared by dissolving in vitriol solution appropriate amounts of antimonous trichloride and antimony (Shanghai Chemicals, Shanghai, P.R. China), respectively. Working standard solutions were obtained by appropriate dilution of the stock standard solution just before use. The $0.02 \mathrm{~mol} \mathrm{~L}^{-1}$ solutions of N-benzoyl-N-phenyhydroxylamine (Tianjin Chemicals, Tianjin, P. R. China) were prepared by dissolving the compound in high purity methanol. A $0.2 \mathrm{~mol} \mathrm{~L}^{-1}$ sodium thiosulphate solution in water was used for reducing $\mathrm{Sb}(\mathrm{V})$. The $\mathrm{pH}$ was adjusted with $0.1 \mathrm{~mol} \mathrm{~L}^{-1}$ hydrochloric acid and ammonia solutions before use.

Standard reference material SRM NIST 1643d Trace Elements in Water (National Institute of Standards and Technology, Gaithersburg, MD, USA) was used for checking the accuracy of the developed method. All reagents used were of SpecPure ${ }^{\circledR}$ grade or at least of analytical reagent grade. Doubly distilled water was used throughout.

\section{Sample Collection and Preparation}

Tap water (pH 8.4, Linfen, P.R. China) and river water ( $\mathrm{pH} 5.6$, Fen River, Linfen, P.R. China) were filtered through a $0.45-\mu \mathrm{m}$ pore size membrane filter (Tianjing Jinteng Instrument Factory, Tianjin, P.R. China), then acidified to $\mathrm{pH}$ of about 2.0 with concentrated hydrochloric acid prior to storage or final use.

\section{Analytical Procedure}

The graphite tubes were pretreated 25 times with the Rh modifier as $20 \mu \mathrm{L}$ of $500 \mu \mathrm{g} \mathrm{mL}^{-1}$

TABLE I

Graphite Furnace Temperature Program for the Determination of Sb

\begin{tabular}{lcccc}
\hline Steps & $\begin{array}{c}\text { Temperature } \\
\left({ }^{\circ} \mathrm{C}\right)\end{array}$ & $\begin{array}{c}\text { Ramp Time } \\
(\mathrm{s})\end{array}$ & $\begin{array}{c}\text { Hold Time } \\
(\mathrm{s})\end{array}$ & $\begin{array}{c}\text { Ar Flow } \\
\left(\mathrm{mL} \mathrm{min}^{-1}\right)\end{array}$ \\
\hline Drying & 80 & 1 & 30 & 250 \\
Pyrolysis & 1000 & 5 & 10 & 250 \\
Atomization & 2200 & 0 & 3 & 0 \\
Furnace Cleaning & 2500 & 1 & 1 & 250 \\
\hline
\end{tabular}

Rh stock solution was injected into the graphite tube and heated in accordance with the method listed in Reference 26.

A 5.0-mL amount of the sample solution was placed into the $10-\mathrm{mL}$ centrifugation tube containing a plug, then a mixture of $0.5 \mathrm{~mL}$ of the BPHA methanol solution and $50 \mu \mathrm{L}$ of chloroform were added with a pipette gun. The mixture was shaken gently for a few minutes, which produced a cloudy solution due to the fine droplets, and the complex was extracted into these fine droplets. The mixture was centrifuged at $4000 \mathrm{rpm}$ for 2.0 minutes and the dispersed fine droplets of chloroform settled. Then, $20 \mu \mathrm{L}$ of the organic phase was injected into the graphite furnace for analysis. Total $\mathrm{Sb}$ was determined after pre-reduction of $\mathrm{Sb}(\mathrm{V})$ to $\mathrm{Sb}$ (III) by sodium thiosulphate at $\mathrm{pH}$ 2.0. The concentration of $\mathrm{Sb}(\mathrm{V})$ was calculated by subtracting the $\mathrm{Sb}$ (III) concentration from the total $\mathrm{Sb}$. The procedure was repeated and a new measurement obtained.

\section{RESULTS AND DISCUSSION}

\section{Effect of Extraction Solvent and Volume}

The selection of an appropriate extraction solvent is important for DLLME. The solvent should be denser than water. Moreover, it should have more capability for the extraction of the compounds of interest and lower solubility in water. Thus, three solvents were evaluated as the extraction solvent, i.e., chloroform, carbon tetrachloride, and methylenechloride. The experimental results demonstrated that chloroform provided higher extraction efficiency than the other organic solvents. Therefore, chloroform was used as the extraction solvent.

In order to examine the effect of the amount of extraction solvent, volumes of $40,50,60,70$, and $80 \mu \mathrm{L}$ were used with the same DLLME procedure. It was found that by increasing the volume of chloroform, the extraction efficiency increased in relation to the increase in extraction solvent volume. However, with a low volume of extraction solvent, a high enrichment factor was obtained. So, $50 \mu \mathrm{L}$ of extraction solvent was selected for use in this study.

\section{Effect of Dispersive Solvent and Volume}

The selection of a dispersive solvent is limited to solvents such as methanol, acetonitrile, ethanol and acetone, miscible with both water and extraction solvents. It was found that methanol provided a higher extraction efficiency than other organic solvents (see Figure 1). Thus, methanol was selected in this study.

The effect of methanol volume on the extraction efficiency was also examined. Various experiments were performed with different amounts of methanol which resulted in a different volume of the 


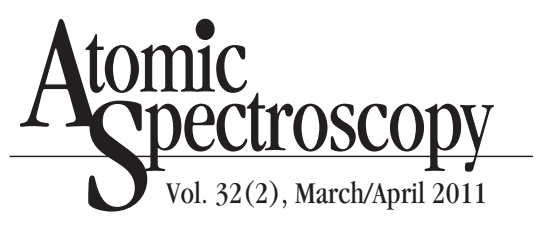

sediment phase. The extraction efficiency increased with an increase in methanol up to $0.5 \mathrm{~mL}$, and then decreased with an increase in volume of methanol above $0.5 \mathrm{~mL}$. Thus, $0.5 \mathrm{~mL}$ of methanol was chosen as the optimum volume.

\section{Effect of BPHA Concentration}

The influence of the concentration of BPHA was also evaluated and the results showed that the extraction efficiency of $\mathrm{Sb}$ (III) increased with an increase in BPHA concentration from $0.1 \mu \mathrm{mol} \mathrm{L}^{-1}$ to $0.5 \mu \mathrm{mol} \mathrm{L}^{-1}$ and then kept constant up to $2.0 \mu \mathrm{mol} \mathrm{L}^{-1}$. A BPHA concentration of $1.0 \mu \mathrm{mol} \mathrm{L}^{-1}$ was employed for further study.

\section{Effect of pH}

The $\mathrm{pH}$ of the sample solution is one of the important factors affecting the formation of complexes and their subsequent extraction. The effect of $\mathrm{pH}$ on the DLLME extraction was studied over the $\mathrm{pH}$ range of 1.0-6.0. It was found that $\mathrm{Sb}$ (III) was completely extracted in the $\mathrm{pH}$ range of 1.0-6.0, but there is virtually no extraction of $\mathrm{Sb}(\mathrm{V})$ over this
$\mathrm{pH}$ range (see Figure 2). Therefore, a $\mathrm{pH}$ of about 2.0 was selected.

\section{Extraction Time}

In DLLME, extraction time is defined as the time elapsing from the incorporation of the mixture of extraction and dispersive agents to the moment centrifugation begins. After forming a cloudy solution, the mixture diffuses quickly into the extraction solvent. In this method, the most time-consuming step (about 5 minutes) was the centrifugation of the sample solution in the extraction procedure. The effect of extraction time was examined from 30 seconds to 10 minutes using the same experimental conditions. The obtained results showed that extraction time had no significant influence on the signal. Because of the large contact surface between the organic and aqueous phase after the formation of the cloudy mixture, the processes of complexation and extraction were very rapid.

\section{Optimization of ETAAS Determination of $\mathbf{S b}$}

Antimony (Sb) is one of the relatively volatile elements, so a certain loss of Sb may occur during the ashing stages. To prevent such losses, use of a chemical modifier was required to increase the $\mathrm{Sb}$ thermal stability. However, the application of liquid solutions as chemical modifiers, i.e., addition to the sample before injection or direct introduction into the graphite tube after sample injection, is a complicated procedure. Therefore, the use of a "permanent" chemical modifier was considered. In the present work, $\mathrm{Rh}$ was chosen as the chemical modifier. The experimental results indicated that the $\mathrm{Rh}$ permanent modifier allowed a higher pyrolysis temperature, showed improved sensitivity and reduced background. The optimized pyrolysis and atomization temperatures were 1000 and $2200{ }^{\circ} \mathrm{C}$, respectively.

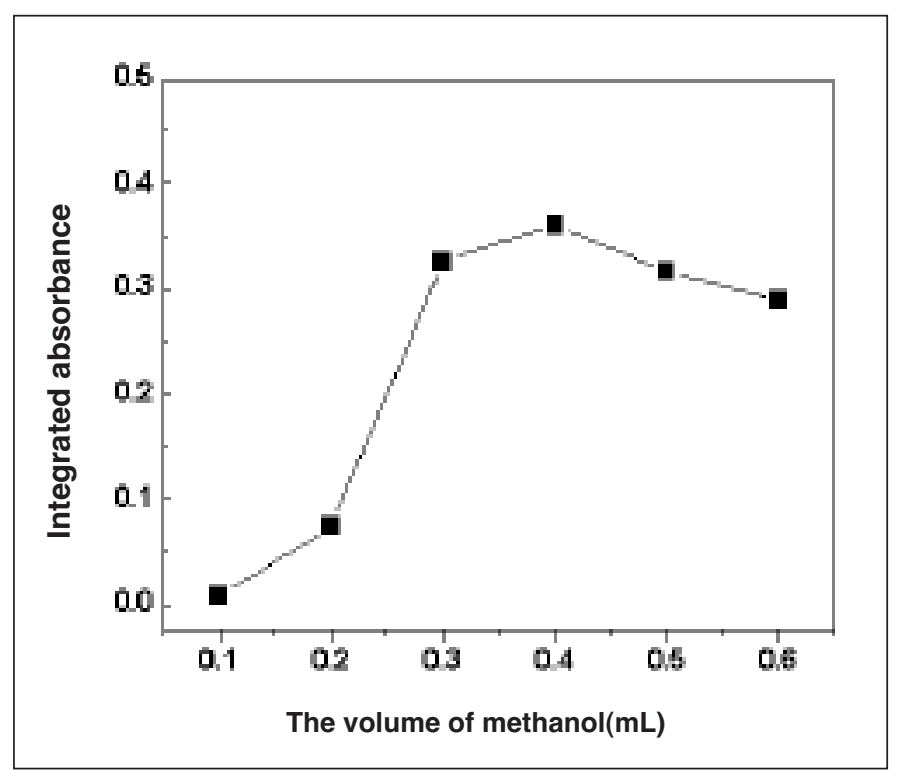

Fig. 1. Effect of the dispersive solvent (methanol) volume on the analytical signals.

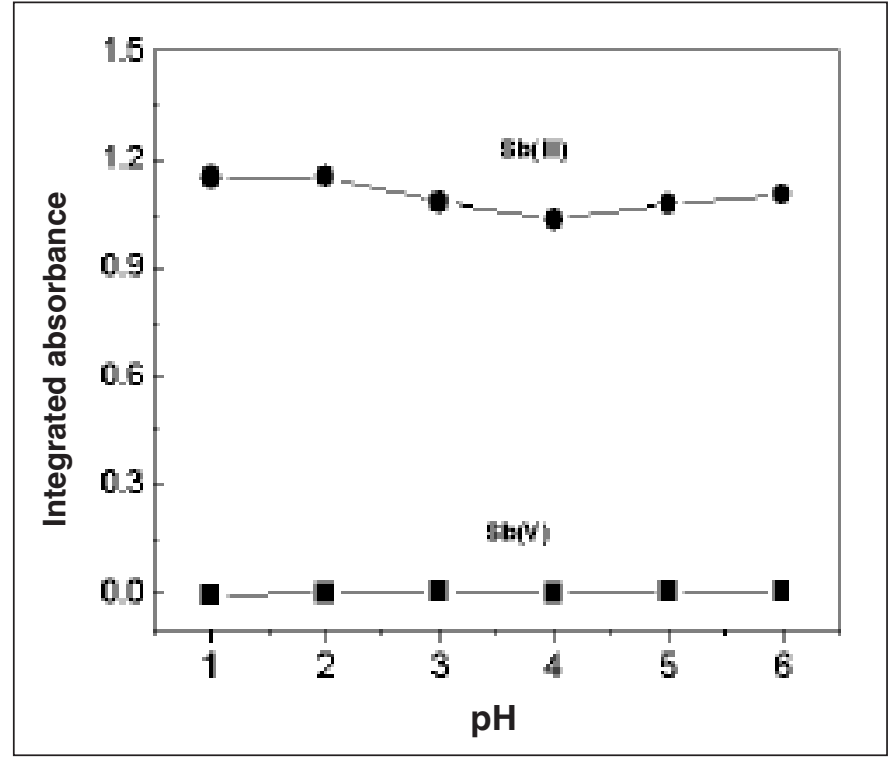

Fig. 2. Effect of $p H$ of the sample solution on the extraction efficiency of Sb(III) and $S b(V)$. 
TABLE II

Determination of Sb Species in Natural Water Samples

\begin{tabular}{cccccccc}
\hline & \multicolumn{2}{c}{ Added $\left(\mu \mathrm{g} \mathrm{L}^{-1}\right)$} & & \multicolumn{2}{c}{ Found $\left(\mu \mathrm{g} \mathrm{L}^{-1}\right)$} & \multicolumn{2}{c}{ Recovery $(\%)$} \\
\hline Samples & $\mathrm{Sb}(\mathrm{III})$ & $\mathrm{Sb}(\mathrm{V})$ & $\mathrm{Sb}(\mathrm{III})$ & Total $(\mathrm{Sb})$ & $\mathrm{Sb}(\mathrm{V})$ & $\mathrm{Sb}(\mathrm{III})$ & $\mathrm{Sb}(\mathrm{V})$ \\
\hline River Water & 0.0 & 0.0 & $<\mathrm{LOD}$ & $0.281 \pm 0.014$ & $0.281 \pm 0.014$ & - & - \\
& 0.2 & 0.2 & $0.201 \pm 0.04$ & $0.665 \pm 0.015$ & $0.464 \pm 0.013$ & 101 & 91.5 \\
Tap Water & 0.0 & 0.0 & $<\mathrm{LOD}$ & $0.191 \pm 0.012$ & $0.191 \pm 0.012$ & - & - \\
& 0.2 & 0.2 & $0.186 \pm 0.013$ & $0.573 \pm 0.015$ & $0.387 \pm 0.011$ & 93.0 & 98.0 \\
\hline
\end{tabular}

\section{Interferences}

The potential of interference in the present system was investigated. The interference is due to the competition of other heavy metal ions for the chelating agent and their subsequent co-extraction with $\mathrm{Sb}$ (III). To evaluate the selectivity of the proposed method, the effect of typical potential interfering ions was investigated. The tolerable limit was taken as a relative error $\leq \pm 10 \%$. The tolerable concentration ratio of foreign ions to $0.5 \mathrm{ng} \mathrm{mL}^{-1} \mathrm{Sb}$ (III) was found to be $2000 \mu \mathrm{g} \mathrm{mL}^{-1}$ for $\mathrm{Na}^{+}$and $\mathrm{K}^{+}$; $1000 \mu \mathrm{g} \mathrm{mL}^{-1}$ for $\mathrm{Ca}^{2+}$ and $\mathrm{Mg}^{2+}$; and $50 \mu \mathrm{g} \mathrm{mL}^{-1}$ for $\mathrm{Ni}(\mathrm{II}), \mathrm{Cu}(\mathrm{II})$, $\mathrm{Al}(\mathrm{III}), \mathrm{Fe}(\mathrm{III}), \mathrm{Pb}$ (II), Zn(II), Mn(II), Cr(VI), and Co(II).

\section{Analytical Performance}

The linear concentration range for $\mathrm{Sb}$ (III) was from 0.03 to $20 \mu \mathrm{g} \mathrm{L}^{-1}$. The calibration function was $\mathrm{A}=0.00518+0.11328 \mathrm{C}$ with a correlation coefficient 0.9997 , where C was the concentration of $\mathrm{Sb}$ (III). The detection limit, calculated according to three times the standard deviation of the blank signals with the preconcentration step, was $0.03 \mu \mathrm{g} \mathrm{L}^{-1}$ for $\mathrm{Sb}(\mathrm{III})$. The relative standard deviation was $3.8 \%$ (c=0.5 $\mathrm{g} \mathrm{L}^{-1}, \mathrm{n}=5$ ) for $\mathrm{Sb}(\mathrm{III})$. The concentration factor, defined as the concentration ratio of $\mathrm{Sb}$ in the organic phase and in the initial solution, was 110 .

\section{Sample Analysis}

The proposed method was applied to the separation and determination of $\mathrm{Sb}$ (III) and total $\mathrm{Sb}$ in different water samples and the analytical results are given in Table II. The recoveries for the spiked samples were in the acceptable range of 91.5-101\%.

To further verify the accuracy of the method, the developed method was applied to the determination of total Sb in certified water sample NIST $1643 \mathrm{~d}$. The analytical result of $53.2 \pm 1.2 \mu \mathrm{g} \mathrm{L}^{-1} \mathrm{Sb}$ in the natural water samples was in good agreement with the certified value of $54.1 \pm 1.5 \mu \mathrm{g} \mathrm{L}^{-1} \mathrm{Sb}$ for NIST $1643 \mathrm{~d}$. No significant differences were observed ( $t$-test, $\mathrm{P}=0.05$ ).

\section{CONCLUSION}

In this work, an effective method for the separation and determination of $\mathrm{Sb}$ (III) and total $\mathrm{Sb}$ has been achieved using dispersive liquidliquid microextraction (DLLME) prior to electrothermal atomic absorption spectrometry (ETAAS) determination with $\mathrm{Rh}$ as the permanent modifier. The method is simple and rapid, with minimal waste generation, offers lower limits of detection $\left(0.03 \mu \mathrm{g} \mathrm{L}^{-1}\right)$ and higher enrichment factors (110) than other reported methods.

\section{ACKNOWLEDGMENTS}

This work was supported by the Natural Science Foundation of Shanxi Province. P.R. China (2009011013-2).

$\overline{\text { Received January 25, } 2011 .}$ 


\section{Atomic \\ Vol. 32(2), March/April 2011}

\section{REFERENCES}

1. M.O. Andreae, C.S. Wong, E. Boyle, K.W. Bruland, J.D. Burton, and E.D. Goldberg (Eds.), Trace Metals in Sea Waters, Plenum Press, New York, pp. 1-19 (1983).

2. B.A. Fowler, P.L. Goering, and E. Merian (Eds.), Metals and Their Compounds in the Environment, $\mathrm{VCH}$, Weinheim, Germany, pp 743-750 (1991).

3. S. GarbÓs, E. Bulska, A. Hulanicki, Z. Fijalek, and K. Soltyk, Spectrochim. Acta Part B, 55, 795 (2000).

4. N.V. Semenova, L.O. Leal, R. Forteza, and V. Cerda, Anal. Chim. Acta 530, 113 (2005).

5. W. Shotyk, M. Krachler, B. Chenz, and J. Zhengy, J. Environ. Monit. 7, 1238 (2005).

6. C.H. Yu, Q.T. Cai, Z.X. Guo, Z.G. Yang, and S.B. Khoo, Analyst 127, 1380 (2002).

7. X.P. Yan, R. Kerrich, and M.J. Henry, Anal. Chem. 70, 4736 (1998)

8. J.Y. Cabon and C.L. Madec, Anal. Chim. Acta 504, 209 (2004).

9. S. Nielsen and E.H. Hansen, Anal. Chim. Acta 343, 5 (1997).

10. Y.L. Feng, H. Narasaki, H.Y. Chen, and L.C. Tian, Anal. Chim. Acta 386, 297 (1999).

11. J.M. Costa-Fernández, F. Lunzer, R. Pereiro-García, A. Sanz-Medel, and N. Bordel-García, J. Anal. At. Spectrom. 11, 1019 (1995).

12. C.B. Ojeda, F.S. Rojas, J.M.C. Pavón, and L.T. Martín, Anal. Bioanal. Chem. 382, 513 (2005).

13. P.B. Barrera, J.M. Pineiro, A.M. Pineiro, and A.B. Barrera, Anal. Chim. Acta 374, 231 (1998).

14. R.E. Rivas, I.L. García, and M.H. Córdoba, Spectrochimica. Acta, Part B, 64, 329 (2009).

15. K.Z. Perenyi, P. Jankovics, E. Sugar, and A. Lasztity, Spectrochim. Acta, Part B, 63, 445 (2008).

16. L. Zhang, Y. Morita, A. Sakuragawa, and A. Isozaki, Talanta, 2007, 72, 723 (2007).

17. M.A. Jeanot, F.F. cantwell, Anal. Chem.,1996, 68, 2236-2240.
18 R.J.A.V. Cleuvenbergen, W.E.V. Mol, and F.C. Adams, J. Anal. At. Spectrom. 31,169 (1988).

19. A.R. Kumar and P. Riyazuddin, Int. J. Environ. Anal. Chem. 87, 469 (2007).

20. M. Kanke, T. Kumamaru, K. Sakai, and Y. Yamamoto, Anal. Chim. Acta 247, 13 (1991).

21. M.B. De la Calle Guntinas, Y. Madrid, and C. Camara, Mikrochim. Acta 109,149 (1992).

22. M. Rezaee, Y. Assadi, M.R.M. Hosseini, E. Aghaee, F. Ahmadi, and S. Berijani, J. Chromatogr., A, 1116, 1 (2006).

23. E.Z. Jahromi, A. Bidari, Y. Assadi, M.R.M. Hosseini, and M.R. Jamali, Anal. Chim. Acta 585, 305 (2007).

24. H.M. Jiang, Y.C. Qin, and B. Hu, Talanta 74,160 (2008).

25. F. P. Pereira, I. Lavilla, and C. Bendicho, Spectrochim. Acta, Part B, 64, 1 (2009).

26. J.B.B. Silva, M.A.M. Silva, A.J. Curtius, and B.Welz, J. Anal. At. Spectrom. 14, 1737 (1999). 